\title{
Undecanoic acid toxicity toward Trichophyton rubrum relies on an oxidative stress status
}

\author{
Tamires A. Bitencourt, Niege S. Mendes, Pablo R. Sanches, Antonio Rossi, Nilce M. Martinez-Rossi \\ University of São Paulo, Ribeirão Preto Medical School, Department of Genetics, Ribeirão Preto-SP, \\ Brazil
}

Keywords: Oxidative stress, dermatophytes, fatty acid, antifungal.

\section{INTRODUCTION}

The fungitoxicity of fatty acids to dermatophytes has long been known. The presence of these compounds in skin and sweat is associated to protection against superficial infections. In this respect, the antidermatophytic activity of undecanoic acid (UDA), a medium-chain saturated fatty acid, is highlighted in the series of $\mathrm{C}_{7: 0-} \mathrm{C}_{18: 0}$ compounds, and it has been used to treat cutaneous mycoses. On the other hand, its mode of action is not entirely understood and seems to be related to non-specific interactions with fungal cell proteins and enzymes as well as to fatty acid metabolism. A high throughput assay was previously performed by our research group to unveil key physiological aspects in T. rubrum response to UDA exposure (Mendes et al, 2018). Among the main pathways involved in UDA detoxification, the response to oxidative stress drew our attention. For this reason, this work aimed to assess the effect of UDA on T. rubrum cellular antioxidant system.

\section{METHODS}

A serial drop dilution assay was carried out to analyze the effect of UDA, menadione, and the association of UDA with menadione on $T$. rubrum mycelial growth. Different concentrations of a conidia suspension were inoculated on 24 well plates (in a range of $10^{6}$ to $10^{2}$ cell $/ \mathrm{mL}$ ), followed by incubation for $96 \mathrm{~h}$ at $28^{\circ} \mathrm{C}$.

The gene expression analysis of two encoding enzymes, Glutathione transferase, and Cytochrome c peroxidase, involved in oxidative stress response were evaluated using rpb2 as the normalizer, and $2^{-\Delta \Delta \mathrm{Ct}}$ method. The relative expression was assessed using T. rubrum grown on Sabouraud (without drugs) as the reference, and the test conditions were menadione $(5 \mu \mathrm{M}, 10 \mu \mathrm{M}, 20 \mu \mathrm{M})$ or UDA $(17.5 \mu \mathrm{g} / \mathrm{mL})$ for 3 and $12 \mathrm{~h}$ of exposure.

\section{REFERENCES}

Mendes, N.S., Bitencourt, T.A., Sanches, P.R., Silva-Rocha, R., Martinez-Rossi, N.M., and Rossi, A. (2018). Transcriptome-wide survey of gene expression changes and alternative splicing in Trichophyton rubrum in response to undecanoic acid. Scientific Reports 8.

\section{ACKNOWLEDGMENTS}
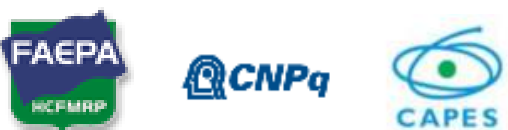

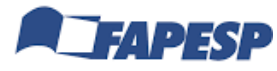

Process number: 2015/23435-8 and 2014/03847-7

\section{RESULTS}

The sensitive phenotype assay showed a marked growth inhibition by UDA in concentration assayed $(12.5 \mu \mathrm{g} / \mathrm{mL})$, and no growth inhibition in the lower concentration tested $(3.125 \mu \mathrm{g} / \mathrm{mL})$, whereas menadione showed a pronounced colony growth reduction in the highest concentrations assayed $(40 \mu \mathrm{M}$ and $20 \mu \mathrm{M})$, followed by a slight reduction in the lower tested concentrations of $10 \mu \mathrm{M}$, and $5 \mu \mathrm{M}$. In both cases, the growth inhibition was in a dosedependent manner. The association of menadione $(5 \mu \mathrm{M})$ with UDA $(3.125 \mu \mathrm{g} / \mathrm{mL})$ showed a possible synergism effect, with a reduction in colony growth similar to menadione concentration of $20 \mu \mathrm{M}$. (Fig. 1)

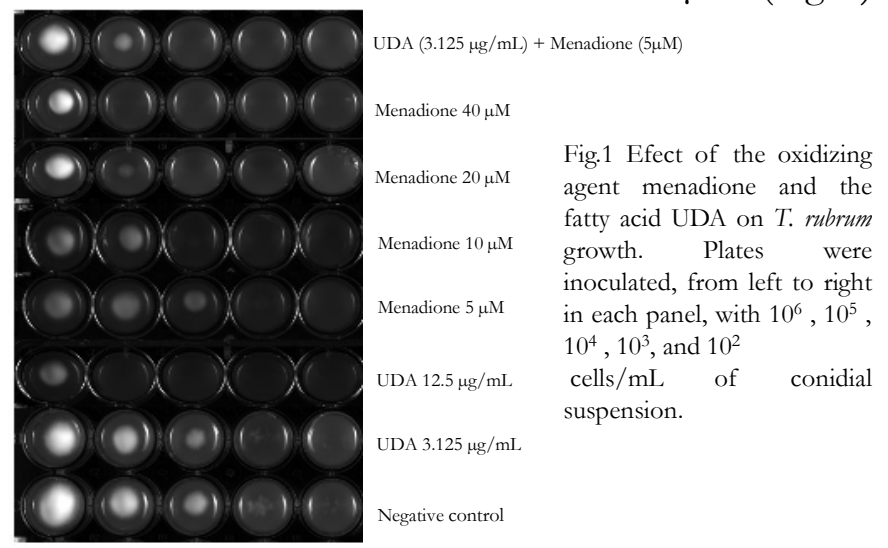

Besides, the gene modulation of the oxidizing enzymes showed their up-regulation after $3 \mathrm{~h}$ of UDA exposure, as well as for menadione exposure. (Fig. 2)
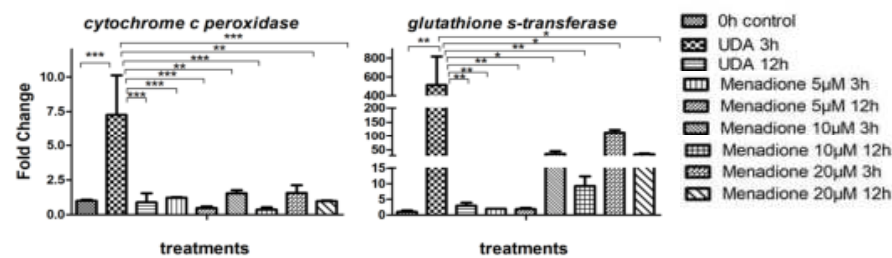

Fig. 2 qRT-PCR for T. rubrum genes encoding the oxidizing enzymes Glutathione transferase, and Cytochrome c peroxidase Signifcantly diferent values are indicated by asterisks $(\mathrm{P}<0.05)$

\section{CONCLUSION}

These results may be related to the first line defence employed by $T$. rubrum to overcome the oxidative stress status, and also hinted the enhance UDA-based antifungal therapy by oxidant agent menadione. Therefore, these data strengthen the cellular antioxidant system as a possible target of UDA. 